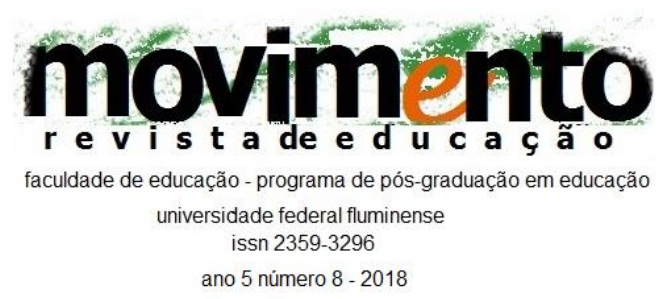

\title{
POLÍTICAS EDUCACIONAIS PARA O ENSINO SUPERIOR DE 2003 A 2012: expansão, precarização e privatização
}

\author{
Denise Bessa Léda \\ Universidade Federal do Maranhão, \\ São Luís, MA, Brasil \\ Ana Paula Ribeiro de Sousa \\ Universidade Federal do Maranhão \\ São Luís, MA, Brasil
}

\begin{abstract}
Resumo
O presente artigo analisa a contrarreforma da educação superior no Brasil e discute como as políticas para a educação superior fomentadas entre 2003 e 2012 se configuram como uma continuidade do projeto de reestruturação desse nível de ensino, na esteira das orientações dos Organismos Internacionais, nos marcos das reformas neoliberais iniciadas na década de 1990. Conclui que, em que pese o discurso da "democratização" e a efetiva expansão quantitativa de vagas e matrículas, as políticas de educação superior têm alavancado o processo de empresariamento do setor e a precarização da Universidade pública.

Palavras-chave: Contrarreforma do ensino superior; Políticas Públicas; Expansão; Precarização; Privatização.
\end{abstract}

\section{EDUCATIONAL POLICIES FOR HIGHER EDUCATION 2003 TO 2012: expansion, precariousness and privatization}

\begin{abstract}
Analysis of the counter-reformation of education in Brazil. Discussion on how policies for superior education put in place between 2003 and 2012 continue the project of restructuration of that level of education, after guidelines of the International Organisms, according to neoliberal reformations taking place in the 1990s. The conclusion is that the here analyzed superior education policies movement, in spit of the speech of "democratization" and the effective quantitative expansion of vacancies and enrollments, has put in motion the process of enterprising and jeopardizing the public University.

Keywords: Counter-reformation of superior education; Public policies; Expansion; Jeopardizing; Privatization.
\end{abstract}




\title{
movimento \\ faculdade de educação - programa de pós-graduação em educação universidade federal fluminense \\ issn 2359-3296 \\ ano 5 número 8 - 2018
}

\section{POLÍTICAS EDUCACIONALES PARA LA ENSEÑANZA SUPERIOR DE 2003 A 2012: expansión, precarización y privatización}

\begin{abstract}
Resumen
Analiza la contrarreforma de la educación superior en Brasil. Discute cómo las políticas para la educación superior fomentadas entre 2003 y 2012 se configuran como una continuidad del proyecto de reestructuración de este nivel de enseñanza, en la línea de las orientaciones de los Organismos Internacionales, en los marcos de las reformas neoliberales iniciadas en la década de 1990. Concluye que, en que pese al discurso de la "democratización" y la efectiva expansión cuantitativa de vacantes y matrículas, políticas de educación superior ha apalancado el proceso de empresarización del sector y la precarización de la Universidad pública.

Palabras clave: Contrarreforma de la enseñanza superior; Políticas públicas; Expansión; La precariedad; La privatización.
\end{abstract}

\section{Introdução}

Não há reforma que concilie uma maioria prepotente e uma minoria desvalida

(Florestan Fernandes)

A citação em epígrafe traduz a problemática de fundo que pretendemos discutir no presente artigo no que concerne as reformas educacionais voltadas para o ensino superior empreendidas de 2003 a 2012, período em que o Partido dos Trabalhadores (PT) ocupou a Presidência da República, inicialmente com Luiz Inácio Lula da Silva (2003 a 2010), por dois mandatos consecutivos e, posteriormente, por Dilma Rousseff (2011-2016), que, embora logrando a vitória eleitoral por dois pleitos, foi destituída do cargo no seu segundo mandato, em maio de 2016, por meio de um golpe empresarial-parlamentar-jurídico-midiático',

\footnotetext{
1 De acordo com Frigotto (2017, p. 23), o movimento que culminou com a instauração do processo de impeachment da Presidenta Dilma Rousseff em 31/08/2016, que alguns analistas caracterizam como um golpe por representar uma ruptura com relação à institucionalidade democrática, uma vez que não foi configurado, de forma incontroversa, o crime de responsabilidade imputado a ela, "[...] tem sua gênese e sustentação nas confederações e institutos privados que representam os grupos detentores do capital local e mundial; na grande mídia monopolista empresarial, parte e braço político e ideológico desses grupos; em setores e figuras do poder judiciário, inclusive na mais alta Corte [...]; em setores do Ministério Público e da Polícia Federal", representantes dos setores da classes dominantes que "[...] organizou-se como tal no coração do Estado e da sociedade civil" (FRIGOTTO, 2017, p. 23). No campo da educação, apoiaram o impeachment representantes dos interesses empresariais, reunidos,
} 


\section{movimento \\ faculdade de educação - programa de pós-graduação em educação universidade federal fluminense \\ issn 2359-3296 \\ ano 5 número 8 - 2018}

que levou ao processo de impeachment da Presidenta e ao fim melancólico do ciclo de administrações petistas à frente do Executivo Federal.

Evocar a frase de Florestan Fernandes nos parece oportuno para tentar compreender o percurso contraditório das políticas educacionais para o ensino superior no referido período, pois, ao mesmo tempo em que fomentou a expansão da rede federal de ensino, tanto por meio das Universidades quanto por meio dos Institutos de educação, ciência e tecnologia, criando oportunidades de estudo para segmentos da população historicamente alijados dos graus mais elevados da hierarquia educacional, contraditoriamente, o fez a partir de um projeto que descaracteriza a Universidade pública como instituição produtora de conhecimentos científicos, filosóficos e artísticos, adotando a perspectiva neoliberal de Educação Terciária ${ }^{2}$ e através de uma expansão precarizada que limita o aspecto progressista dessa política. Por outro lado, fomentou o crescimento exponencial do setor privado-mercantil, favorecendo 0 aprofundamento da mercantilização e do empresariamento do setor, enfraquecendo o caráter da educação superior como direito público e universal e legitimando a concepção privatista de educação como mercadoria de alto valor e como um investimento privado.

sobretudo, em torno do Movimento "Todos pela Educação" e representantes do pensamento conservador genericamente denominado "Movimento Escola sem Partido" (idem).

2 O Banco Mundial (2003) adota a definição da Organização para Cooperação e Desenvolvimento Econômico - OCDE, a qual entende por educação terciária o "[...]nível ou etapa de estudos posteriores à educação secundária" (BM 2003, p. IX). O sistema de educação terciária é composto por instituições como universidades públicas e privadas, institutos de educação superior e politécnicos, assim como outros cenários, como escolas secundárias, locais de trabalho, ou cursos livres e grande variedade de entidades públicas ou privadas (BM, 2003). A adoção do termo vai ao encontro das proposições dos organismos internacionais - o citado Banco Mundial e a Unesco (1998), principalmente - no sentido de promover a expansão, por eles denominada "massificação", desse nível de educação, que só pode ser alcançada pela implementação de um sistema diferenciado, composto por instituições com variados fins, para atender a um perfil igualmente diversificado de estudantes. 


\section{movimento \\ faculdade de educação - programa de pós-graduação em educação universidade federal fluminense \\ issn 2359-3296 \\ ano 5 número 8 - 2018}

É certo que essas reformas não foram inauguradas no período em análise, pois seu escopo se delineava desde a década de 1980, enquanto parte do projeto político da burguesia no sentido de refrear as tendências democráticas que se intensificavam no período de redemocratização do país e de recompor sua hegemonia de classe, no qual um projeto de universidade pública autônoma não estava em questão.

Segundo sintetiza Minto (2014), tal projeto "antiuniversidade", longamente gestado e continuado durante os anos 2000, visa a se contrapor a universidade estatal, gratuita, laica e regida pelo princípio da indissociabilidade entre ensino, pesquisa e extensão, que apresenta os requisitos mínimos para garantia de uma existência autônoma. Portanto, esse projeto dos governos neoliberais "não implica o fim da universidade, mas antes a restrição ao máximo de um determinado tipo de instituição e dos fins que é capaz de cumprir" (MINTO, 2014, p. 297). Para os adeptos desse pensamento, o país não precisa de um sistema universitário amplo e de massas, ideologicamente denominado como "modelo único"3.

O principal sustentáculo ideológico do discurso reformista seria a necessidade de "democratizar" o acesso ao ensino superior no Brasil, considerado demasiado elitista e excludente em relação à população mais pobre. Além disso, considerado caro e insustentável a longo prazo pelo fundo público, já que absorve recursos que poderiam ser destinados a outros níveis de ensino. Assim, tal argumento justifica que a educação superior não pode se expandir somente a cargo do Estado, a participação da sociedade civil e do setor privado torna-se indispensável.

\footnotetext{
${ }^{3}$ Minto (2014) problematiza a tese da existência de um suposto "modelo único" baseado nas experiências europeias, sobretudo da universidade de pesquisa, que tenha se consolidado no Brasil ao longo do século XX e demonstra o caráter ideológico dessa tese que visa a legitimar a ofensiva neoliberal sobre a universidade pública estatal, universal e laica.
} 


\section{movimento \\ faculdade de educação - programa de pós-graduação em educação universidade federal fluminense \\ issn 2359-3296 \\ ano 5 número 8 - 2018}

Sobre o mesmo argumento, a retórica reformista defende que a educação superior não pode se expandir a partir de um "modelo único", especialmente o universitário, considerado oneroso e impermeável às demandas do mercado. Portanto, defende a flexibilização das instituições de ensino superior e das modalidades de cursos, lançando mão de estratégias que possam tornar esse nível de ensino mais acessível e mais conectado às necessidades do mercado (EaD, certificação por módulos, certificação por competências, bacharelados interdisciplinares, cursos sequenciais, dentre outros).

Portanto, a partir do discurso da "democratização" das oportunidades e como parte da estratégia de atender de forma subordinada as demandas dos "de baixo", ou seja, dos setores nos quais se situa a principal base de sustentação do governo federal, a expansão das vagas no ensino superior foi um grande marco das políticas educacionais no período, assim como o avanço da ideologia privatista neoliberal, que se "adensa" ${ }^{4}$ no setor educacional.

A partir dessas contradições que buscaremos analisar o percurso das políticas educacionais para o ensino superior no período de 2003 a 2012, buscando evidenciar aspectos que consideramos centrais, contraditórios e complementares: a expansão precarizada do setor público e o fortalecimento do setor privado-mercantil.

\footnotetext{
${ }^{4}$ Minto (2014) analisa que, a partir da década de 1990, há um "adensamento privatista", no âmbito das políticas educacionais, no sentido de adequar a educação à lógica do capital tendo como marco a atual LDB. Para o autor, esse adensamento se dá de forma absoluta (crescimento das IES privadas e de sua presença no campo da educação superior) e de forma relativa no interior das IES e na forma de sua relação com a sociedade e o Estado.
} 


\section{movimento \\ faculdade de educação - programa de pós-graduação em educação universidade federal fluminense \\ issn 2359-3296 \\ ano 5 número 8 - 2018}

\section{Contextualização das políticas recentes para o ensino superior (2003-2012)}

A reforma universitária que vem sendo empreendida no Brasil a partir dos anos 1990, apresenta como alvo o modelo universitário baseado na articulação entre ensino-pesquisa-extensão e no desenvolvimento da pós-graduação, que foi consagrado na Constituição Federal de 1988 (MANCEBO, MAUÉS e CHAVES, 2006) e instituído como padrão para o desenvolvimento da universidade pública. Portanto, um dos pilares do discurso reformista foi o ataque a esse "modelo ideal" ou "padrão único" de organização institucional do ensino superior, com base nas orientações dos organismos internacionais e sustentado pela ideologia privatista.

Utiliza-se o argumento de que os gastos do Estado com a oferta do ensino superior universitário tornavam inviável sua manutenção em detrimento dos demais níveis de ensino, os quais precisavam ser mais bem assistidos pelo Estado. Além disso, levanta-se a necessidade de "democratização" do acesso ao ensino superior, considerado demasiadamente elitista, supostamente pela "incapacidade" do setor público em atender toda a sua demanda por meio das universidades públicas, cujo atendimento se limita a um segmento que, supostamente, poderia custear seus estudos ${ }^{5}$.

Portanto, em que pese o caráter ideológico de tais posições, em nome da "democratização" do ensino superior, as reformas dos anos 1990 privilegiaram a expansão do setor privado, tendo como marco a diversificação institucional das IES - admitida pela Lei de Diretrizes e Bases da Educação Nacional (Lei 9.394)

\footnotetext{
${ }^{5}$ Diversos estudiosos, dentre eles Mancebo (2004), contestam essa afirmação com dados estatísticos, concluindo que aproximadamente $1 / 3$ dos alunos das instituições de ensino da rede pública fazem parte dos $10 \%$ mais ricos da população. Entretanto, não são poucos os críticos da gratuidade do ensino superior público, pois o tema é constantemente abordado no conjunto da contrarreforma do ensino superior em curso, a exemplo do projeto de emenda à Constituição que tramita no Congresso Nacional desde 1995 (PEC 123/95), o qual modifica o art. 206 da CF 1988 e autoriza a cobrança de mensalidades no ensino superior público "compatível com a renda familiar".
} 


\section{movimento \\ faculdade de educação - programa de pós-graduação em educação universidade federal fluminense \\ issn 2359-3296 \\ ano 5 número 8 - 2018}

de 1996 e regulamentada pelos decretos n. 2.207/97, 2.306/97 e 3.860/016 - e a reestruturação das universidades públicas, a partir do argumento da "modernização" de suas estruturas administrativas e acadêmicas, visando a torná-las mais eficientes e produtivas e menos onerosas no âmbito do amplo movimento de reforma do Estado?.

O desenvolvimento quantitativo do setor, impulsionado pela iniciativa privada nos anos 1990, valendo-se da diversificação e da flexibilização empreendidas pela legislação vigente, fez com que se enfraquecesse a universidade de pesquisa, concentrada no setor público, consolidando-se a tendência de expansão do setor privado-mercantil, sobretudo através de instituições não-universitárias. O período em análise conserva e aprofunda algumas das características do programa neoliberal, tendo em vista consolidar as reformas necessárias para adequar a educação superior aos interesses do capital. De acordo com alguns estudiosos (LIMA, 2005; CASTELO, 2013; MACIEL, 2010), os anos 2000 caracterizam uma nova configuração do neoliberalismo no Brasil, implementado especialmente a partir dos governos de Lula da Silva (2003-2010) e de Dilma Rousseff (2011-2016), o qual consiste em combinar políticas econômicas de corte neoliberal com políticas sociais redistributivas de caráter compensatório, baseado em um consenso de que o sincretismo entre o Estado e o mercado seria a base para a restauração "estabilidade econômica" com "justiça social".

\footnotetext{
${ }^{6}$ Tais dispositivos flexibilizam a extensão do preceito constitucional contido no art. 207 da CF 1988, de modo que apenas as IES organizadas como universidades estariam obrigadas à observância desse dispositivo constitucional e aos demais perfis de organização criados a partir desta legislação (faculdades isoladas, faculdades integradas, institutos superiores de educação e centros de educação tecnológicas) seria facultado o desenvolvimento da pesquisa e da extensão. e teriam prerrogativas de autonomia reduzidas.

${ }^{7}$ A partir da década de 1990, as estratégias e as ações oficiais para a reforma do ensino superior estão associadas a uma reforma mais ampla do aparelho de estado a partir dos pressupostos neoliberais, cujo marco é a criação, em 1995, no governo Fernando Henrique Cardoso, do Ministério de Administração e Reforma do Estado - MARE, que, dentre outras medidas, adota a perspectiva gerencialista de administração do aparelho estatal, a qual trará impactos diretos sobre a universidade.
} 


\section{movimento \\ faculdade de educação - programa de pós-graduação em educação universidade federal fluminense \\ issn 2359-3296 \\ ano 5 número 8 - 2018}

Uma ideologia que atravessou e constituiu o discurso "desenvolvimentista" e foi recuperada, pelos governos de coalizão de classes, conduzidos pelo Partido dos Trabalhadores no período de 2003-2016, com base no projeto identificado como "novo desenvolvimentismo" ou "social desenvolvimentismo"8 (LIMA, 2017, p. 94).

Nesse contexto, busca-se combater as mazelas do neoliberalismo, combinando algumas premissas liberais da social-democracia, com vistas a "humanizar" o capitalismo por meio de políticas sociais de alívio à pobreza e de uma maior aproximação com a sociedade civil. Por outro lado, mantém-se a ortodoxia neoliberal no que se refere aos fundamentos da política econômica. Esse movimento visa a apaziguar a questão social e ainda cooptar as lideranças e os movimentos sociais de contestação da ordem, além de enfraquecer os sindicatos e de colocar as suas reinvindicações no nível econômico-corporativo.

Nesse sentido, os governos do PT elevam a um novo patamar o padrão de desenvolvimento do neoliberalismo no Brasil (MACIEL, 2010; BOITO JR., 2006) através da política de conciliação de classes, ampliando as políticas sociais e garantindo a manutenção do receituário econômico neoliberal.

Com isso, os governos do PT contribuíram para a alienação e o apassivamento das classes trabalhadoras, as quais passam a endossar o seu projeto "neoliberal moderado" (MACIEL, 2010) e, por outro lado, mantiveram os ganhos expressivos da burguesia interna e externa por meio do direcionamento mantido para a política econômica, evidenciando que se trata de uma continuidade do projeto neoliberal que se instaurou no Brasil desde a década de 1990. Conforme a análise de Frigotto (2017, p. 22),

As reformas de base, necessidade fundamental para superar a desigualdade abismal que condena a grande maioria do povo brasileiro a uma vida precária, foram postergadas. Nos oito anos do governo Lula da Silva e nos quatro anos de sua sucessora Dilma Rousseff, os grandes empresários e o capital financeiro não

8 Sobre os conceitos de "novo desenvolvimentismo" ou "social desenvolvimentismo", ver Sampaio Jr. (2012) e Castelo Branco (2009). 


\section{movimento \\ faculdade de educação - programa de pós-graduação em educação universidade federal fluminense \\ issn 2359-3296 \\ ano 5 número 8 - 2018}

foram confrontados, pelo contrário, continuaram ganhando até mais do que no governo Fernando Henrique Cardoso, especialmente no período de forte expansão da economia brasileira.

Não por acaso, por conta da engenharia política de conciliação de classes efetivada durante os governos do Partido dos Trabalhadores, a qual garantiu sua continuidade por quatro pleitos e uma legitimidade praticamente incontestável, foi possível desenvolver e aprofundar pontos da agenda neoliberal associados a algumas conquistas sociais para as classes trabalhadoras e incorporadas ao projeto político e econômico das classes dominantes de forma subordinada. Tal estratégia constituiu, conforme Lima (2017, p. 93), “um novo 'acordo pelo alto' na história brasileira, demarcando o período de 2003 a 2016".

De acordo com Lima (2017), a política de coalização de classes é a manifestação da contrarrevolução preventiva e prolongada na atualidade ${ }^{9}$. Nessa perspectiva, em grande medida, a implementação de políticas aparentemente progressistas está articulada a estratégias contrarrevolucionárias no sentido de incorporar subordinadamente as demandas dos de baixo, contribuindo para a consolidação da hegemonia burguesa em sua atual fase de realização ${ }^{10}$.

Segundo Dias (2006), a arquitetura de uma conciliação de classes era necessária para a continuidade das reformas políticas e econômicas que estavam sendo implementadas desde os governos anteriores. A liderança e o carisma de Lula foram fundamentais para direcionar esse processo ${ }^{11}$, devido à

\footnotetext{
9 Entretanto, a autora pontua que, com o impeachment de Dilma Rousseff em 2016, estava esgotada a fase da contrarrevolução neoliberal baseada na política de conciliação de classes, inaugurando uma nova era contrarrevolucionária, capitaneada pelos segmentos ultraconservadores da burguesia na tarefa de garantir o enfrentamento da queda das taxas de lucro do capital, sem lançar mão das estratégias anteriores de contrarrevolução, avançando sobre os direitos da classe trabalhadora mais do que nunca.

10 Oliveira (2018) e Boito Jr.(2006) chamam a atenção para a peculiaridade desse momento, alertando que não se trata de um processo de hegemonia clássico. O primeiro caracteriza tal processo de "hegemonia às avessas" e o segundo "hegemonia regressiva".

${ }_{11}$ André Singer (2009), caracteriza esse fenômeno como Lulismo, um tipo específico de ação bonapartista de base populista exercida pelo presidente a partir do Estado, organizando, de cima
} 


\section{movimento \\ faculdade de educação - programa de pós-graduação em educação universidade federal fluminense \\ issn 2359-3296 \\ ano 5 número 8 - 2018}

sua liderança bonapartista de base populista exercida sobre as massas, sobretudo as subproletarizadas, as quais tiveram seus interesses contemplados de forma subordinada ao projeto econômico neoliberal, além de sua capacidade de articulação facilitada pela sua postura conciliadora e pragmática, o que possibilitou o apoio da burguesia.

No entanto, a desarticulação política dos movimentos sociais de esquerda e o seu aparelhamento por parte do governo demonstram a permanência e a intensificação da marca corporativista do nosso Estado. O "transformismo", segundo Coutinho (2006, p. 193), "[...] abriu assim caminho para uma maior e mais estável consolidação da hegemonia neoliberal entre nós”.

No âmbito das políticas sociais, percebe-se uma tendência a contemplar os mais pobres, seguindo uma orientação claramente exarada dos organismos internacionais no sentido do "alívio a pobreza"12, visando a obter estabilidade e coesão social necessárias para o aprofundamento do neoliberalismo no país, sem que houvesse logicamente prejuízos dos ganhos das classes proprietárias.

O discurso da "democratização" do acesso ao ensino superior emerge com força, associando a expansão da rede federal com o aprofundamento dos mecanismos de privatização do setor. Isso fortalece a atuação de grupos privados na oferta de cursos em diversas modalidades (graduações presenciais, EaD, cursos sequenciais, modulares, pós-graduação lato e stricto sensu) e com diferentes formatos institucionais (faculdades, escolas isoladas, institutos de educação, centros universitários e universidades). Essa diversificação e a expansão são

para baixo, a ação política desorganizada dessas camadas sociais, expressa através de apoio ao governo.

12 As políticas de alívio à pobreza constituem uma importante orientação dos organismos internacionais no sentido de equacionar a "questão social" e de garantir a coesão social. A educação é vista como importante mecanismo para a redução da pobreza, no sentido de aumentar a produtividade do trabalho, reduzir a taxa de natalidade, melhorar a saúde dessas pessoas e fomentar a aprendizagem ao longo da vida. Ver NEVES e PRONKO, 2008. 


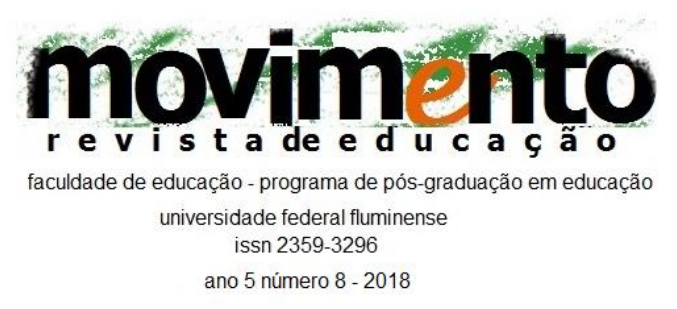

favorecidas pela legislação anterior e pelos programas de transferência de recursos públicos e de renúncia fiscal instituídos no período, os quais flexibilizaram a configuração do setor e aprofundam sua privatização.

De acordo com Rosar (2017),

Mantendo-se, desde o governo FHC, uma política ortodoxa de beneficiamento dos setores privados, predominantemente no setor financeiro, por um lado, e por outro, de redução do financiamento dos serviços públicos, os governos de Lula da Silva e Dilma Rousseff introduziram medidas de amortização da miséria de dos conflitos, adotando uma política de programas sociais focais (Bolsa Família, Minha Casa, minha vida, PROUNI, REUNI, Pronatec), além de realizarem a expansão das universidades públicas e dos Institutos Federais de Educação (ROSAR, 2017, p. 112).

\section{Políticas para a educação superior no período 2003-2012: expansão, privatização e precarização}

Conforme pontuamos acima, o discurso da desresponsabilização do Estado e o avanço da ideologia privatista irão dar o tom das reformas neoliberais para o ensino superior. Sobre a justificativa da "democratização" do acesso a esse nível de ensino, a partir da aplicação do receituário dos organismos internacionais, tais reformas visam à consolidação do sistema de educação terciária no Brasil, por meio do desmonte da Universidade pública e através das políticas que induzem a expansão precarizada das IFES. Além disso, promovem favorecimento do setor privado através da criação e da ampliação de políticas e de programas de transferência direta de recursos públicos ou de renúncia fiscal para as instituições privadas ${ }^{13}$.

\footnotetext{
${ }^{13}$ Para Chaves (2015), são políticas que transferem o financiamento público para o setor privado: as isenções tributárias, as isenções do pagamento do salário-educação, as bolsas de estudo para alunos carentes via Fundo de Financiamento ao Estudante de Ensino Superior (FIES), os empréstimos financeiros a juros subsidiados pelo Banco Nacional de Desenvolvimento Econômico e Social-BNDES, o Programa Universidade para Todos - PROUNI.
} 


\section{movimento \\ faculdade de educação - programa de pós-graduação em educação universidade federal fluminense \\ issn 2359-3296 \\ ano 5 número 8 - 2018}

Esse processo teve início em 2003 com a formulação de propostas elaboradas pelo grupo de trabalho interministerial para a reforma universitária ${ }^{14}$ e se consubstancia no projeto de lei 7.200/06 ${ }^{15}$. Conforme analisa Mancebo (2004, p. 846),

Partindo da constatação de que o Sistema de Educação Superior Federal necessita de regulação orgânica, fundada em princípios contemporâneos, o governo pretende aprovar uma lei que redefinirá os rumos da universidade brasileira. A valer as pretensões do Ministério, a nova lei será ampla e deverá abranger tanto a universidade pública como regular a relação do MEC com as instituições de ensino superior privadas.

Ressalte-se que a não aprovação da lei da reforma universitária, pelo esgotamento das tentativas de estabelecimento de consensos acerca de seus diversos temas (CÊA, 2006), não impediu que o governo desse continuidade ao processo.

Para tanto, lançou mão de outros mecanismos legais, os quais fornecem um preâmbulo da concepção teórica, da inspiração política e de direcionamento prático à reforma do ensino superior proposta pelo governo federal. Como exemplo, podemos citar o Sistema Nacional de Avaliação do Ensino Superior SINAES (Lei 10.861/04); A Lei dos incentivos a inovação e à pesquisa científica e tecnológica no ambiente produtivo (Lei 10.973/04); As Parcerias PúblicoPrivada (PPP), no âmbito da administração pública (Lei 10.973/04); o Programa Universidade Para Todos - PROUNI (Lei 11.096/05); Criação da Universidade Aberta do Brasil - UAB (Decreto no. 5.800/2006); o Programa de Apoio a Planos de Reestruturação e Expansão das Universidades Federais - REUNI (Decreto

14 grupo de trabalho interministerial (GTI) foi instituído em 20/10/2003 e composto pelo Ministério da Ciência e Tecnologia, Planejamento, Fazenda e Educação. É coordenado pela Casa Civil e pela secretaria geral da presidência e tem como objetivo analisar a situação atual e apresentar plano de ação visando à reestruturação, desenvolvimento e democratização das IFES no prazo de 60 dias. Desse grupo de trabalho, resultou no documento "Bases para o enfrentamento da crise emergencial das universidades federais e roteiro para a reforma universitária brasileira".

15 Sobre o conteúdo do projeto e o processo de tramitação, ver Cêa (2006). 


\section{movimento \\ faculdade de educação - programa de pós-graduação em educação universidade federal fluminense \\ issn 2359-3296 \\ ano 5 número 8 - 2018}

6.069/2007); o Fundo de Financiamento Estudantil (FIES) (Lei n. 10.260/01), dentre outras. Tais medidas, incidem sobre a autonomia universitária, fomentam a reestruturação e a expansão precarizadas das instituições públicas e o fortalecimento do setor privado/mercantil.

Dentre as medidas citadas, além de outras que constituem o arcabouço jurídicopolítico e que conferem a orientação prática da contrarreforma ${ }^{16}$ do ensino superior implementada pelo governo federal no período de 2003-2012, daremos destaque àquelas que fomentam a expansão precarizada do ensino público de forma mais direta, contribuindo para a desconstrução da universidade pública, e as que ampliam o processo de privatização do ensino por meio do fortalecimento do setor privado-mercantil.

Um dos argumentos que sustentam a concepção da reforma do ensino superior em curso é a ideia de educação como um "bem público", o qual reforça a diluição das fronteiras entre público e privado, direito e mercadoria, característica do "Estado gerencial"17. Assim, uma vez reafirmado o caráter de "bem público" da educação e a prestação desse serviço público para o conjunto da sociedade pelas instituições públicas e privadas, está naturalizada a alocação de verbas públicas para as instituições privadas e o financiamento privado das IES públicas (LIMA, 2013). Além disso, permite a participação da "sociedade civil"18 e do setor

\footnotetext{
${ }^{16}$ De acordo com o Sindicato Nacional dos Docentes do Ensino Superior (ANDES-SN), o que está em curso é uma contrarreforma, pois, ao contrário de ampliar direitos, as propostas e encaminhamentos direcionados à educação superior apontam para a deterioração do ensino público e para a restrição de direitos no sentido do aprofundamento das reformas estruturais do Estado, iniciadas na década de 1990 (CÊA, 2006).

17 Modelo de gestão estado adotado a partir da reforma aparelho de estado instituída pelo Ministério de Administração e Reforma do Estado - MARE na década de 1990. Uma de suas principais características é a noção de "publicização" ou de público não estatal.

${ }_{18}$ No sentido aqui empregado, o conceito de "sociedade civil" compreende um reordenamento da relação público-privado como justificativa da intervenção e da atuação do setor privado nas instituições de interesse público, guiado pelo espírito da reforma gerencial do aparelho de Estado implementada no governo Cardoso, em que o Estado possa dividir responsabilidades e ações com o setor privado. Sobre o conceito de sociedade civil sobre essa ótica, ver Lima (2005).
} 


\section{movimento \\ faculdade de educação - programa de pós-graduação em educação universidade federal fluminense \\ issn 2359-3296 \\ ano 5 número 8 - 2018}

produtivo nas instituições estatais de ensino superior, inspirando a inovação, promovendo a troca de conhecimentos e aproximando a universidade das demandas da sociedade.

Essa ideia justifica a implementação de medidas práticas nesse sentido, que favorecem a expansão do setor privado via recursos públicos, como é o caso dos programas de transferência e renúncia fiscal, e a ingerência das empresas na universidade pública, através de "parcerias", por meio das quais o setor privado direciona o desenvolvimento das pesquisas e se apropria de seus resultados, assim como se utiliza dos espaços e profissionais da Universidade, o que tende a reduzir sua autonomia, a exemplo da Lei de Inovação Tecnológica (Lei 10.973/04) ${ }^{19}$ e da lei que regulamenta as parcerias público-privadas (Lei n.o $11.079 / 04)^{20}$, associadas à atuação das Fundações de Apoio no âmbito das universidades.

Tais políticas fomentam a ideia do "docente empreendedor" (ANDES, 2013b, p. 23) como aquele capaz de captar recursos no mercado para financiar seus projetos, que muitas vezes são encaminhados de forma heterônoma, conforme o interesse dos financiadores, cujos os resultados são "compartilhados" com o setor privado.

Essa conduta evidencia uma incoerência basilar, uma vez que o setor privado praticamente não financia pesquisa no Brasil, como pode fazer proveito dos resultados? Sobre o financiamento, vale lembrar que são as universidades públicas as responsáveis por $90 \%$ da pesquisa básica e aplicada no país (POLI, 2017).

\footnotetext{
${ }^{19}$ Sancionada no governo Lula, esta lei permitiu a alocação de recursos públicos para empresas que desenvolvem projetos de "inovação" e facilitou a utilização da infraestrutura das IES públicas e seus recursos humanos pela iniciativa privada. Além disso, prevê a gratificação (ferindo a isonomia salarial) de professores-pesquisadores que contribuíssem com esses projetos.

${ }^{20}$ Em 2016 foi sancionado o novo Marco Legal de Ciência e Tecnologia (Lei 13.243/2016), o qual facilita as parcerias público-privadas na produção de ciência, tecnologia e inovação.
} 


\section{movimento \\ faculdade de educação - programa de pós-graduação em educação universidade federal fluminense \\ issn 2359-3296 \\ ano 5 número 8 - 2018}

Essa concepção tem reforçado a noção de competitividade e fomentado o produtivismo entre os docentes das universidades, reforçado o "capitalismo acadêmico"21 (Slaughter y Leslie, 1997 apud MANCEBO, 2011). Desse modo, "Formas de funcionamento desiguais e contraditórias são geradas nas universidades, que mediante ações dos docentes empreendedores aproximam a instituição das empresas e do mercado" (MANCEBO, 2011, p. 82). Por meio desses mecanismos, tem se operado um processo de privatização interna das instituições públicas, através da transferência de conhecimentos produzidos via demandas do mercado, o que coloca em alerta a questão da autonomia universitária e chama atenção para a conversão da universidade em "organização social" (CHAUí, 2001)22.

Essa ideia tem sido, juntamente com a necessidade de redução dos gastos públicos (estatais) em educação superior ${ }^{23}$, um dos pilares para a ampliação da atuação do setor privado na oferta direta da educação superior. Inclusive através

\footnotetext{
21 Segundo Mancebo (2011), capitalismo acadêmico refere-se ao uso que a universidade faz do capital humano dos docentes com o propósito de incrementar seus recursos, incentivando e induzindo um conjunto de iniciativas e de comportamentos economicamente orientados para a obtenção de financiamentos externos.

${ }^{22}$ De acordo com Chauí (2001), a ação administrativa transformou a Universidade de instituição social em organização social, ou seja, uma entidade isolada e administrada cujos sucesso e eficácia se medem em termos de gestão de recursos e estratégias de desempenho, o que a autora denomina "Universidade operacional".

${ }^{23}$ Estudo do Ministério da Fazenda, intitulado "Gasto social do governo central: 2001 e 2002" (2003), aponta o modelo de financiamento das instituições públicas de ensino superior como um grande "obstáculo" às metas sociais do governo e que os recursos do governo central para o ensino superior beneficiam apenas indivíduos que se encontram entre os $10 \%$ mais ricos da população. O documento considera ainda que "[...] a canalização de grande parte do orçamento da educação para o financiamento das instituições federais de ensino superior reduz o montante de recursos disponível para os demais estágios da educação. Considerando a questão da equidade, essa política produz distorções relevantes, constituindo-se no componente do gasto em educação de maior regressividade" (BRASIL, 2003, p. 35).
} 


\section{movimento \\ faculdade de educação - programa de pós-graduação em educação universidade federal fluminense \\ issn 2359-3296 \\ ano 5 número 8 - 2018}

de recursos públicos, como é o caso do Programa Universidade para Todos $(\text { PROUNI })^{24}$ e do Programa de Financiamento estudantil (FIES $)^{25}$.

Além dessas medidas, outras formas de transferência diretas e indiretas de recursos públicos para o privado têm fomentado o empresariamento do ensino superior, o que facilita o sucateamento das universidades públicas, afinal, são elas as mais afetadas com os constantes cortes e os contingenciamentos de recursos, além de constrangimentos gerados por meio da necessidade de obter recursos junto ao mercado para custeio de suas atividades.

Desse modo, conforme apontam Neves e Pronko (2008), tais políticas configuram dois tipos articulados de privatização da educação superior em curso no Brasil: 1) a privatização pelo empresariamento desse nível de ensino pela criação de uma nova burguesia de serviços educacionais, estimulada pelo próprio governo; 2) a privatização da educação pública por meio do financiamento empresarial dos projetos educacionais e pela disseminação de seu modo de ser no desenvolvimento de suas atividades.

Passemos então ao outro aspecto da reforma do ensino superior que nos interessa analisar: a expansão precarizada do setor público, tomando como recorte as universidades federais. Com o objetivo de atingir o cumprimento das

24 O PROUNI foi criado em 2004 (lei n. 11.096/2005) e tem como finalidade a concessão de bolsas de estudos integrais e parciais a estudantes de graduação e de cursos sequenciais de formação específica em instituições privadas de ensino superior. As instituições que aderem ao programa recebem isenção de tributos, representando, portanto, uma forma de financiamento indireto. De acordo com Chaves (2015), o PROUNI representava $12 \%$ do total da renúncia tributária vinculada a educação em 2013, o que tem contribuído muito mais para a mercantilização do ensino do que para a redução das desigualdades sociais, pois, "Apesar do discurso ideológico propalado pelo governo federal de que o PROUNI é um programa destinado a inserir os pobres no ensino superior, na prática, tornou-se mais um dos mecanismos de indução da expansão do setor privado" (CHAVES, 2015, p. 437).

25 O FIES é um programa regulamentado pela Lei 10.260/2001 e destinado a financiar prioritariamente estudantes de cursos de graduação matriculados em instituições privadas com juros subsidiados. 


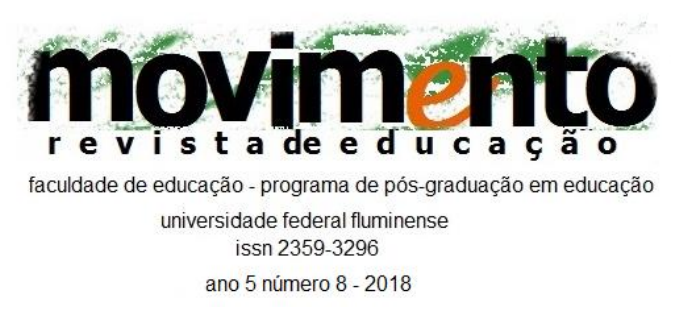

metas do Plano Nacional de Educação (2001-2011) - matricular 30\% da população correspondente à faixa etária do ensino superior e $40 \%$ desta no setor público - as ações do governo em relação à expansão das universidades federais têm início em 2003. A primeira fase do programa de expansão (Expansão I) compreende o período de 2003 a 2007 e teve como principal meta interiorizar o ensino superior público federal por meio da criação de novas universidades e de campus em regiões interioranas.

De acordo com o Balanço social da Sesu (2003-2014) (BRASIL, 2014), na primeira fase do programa de expansão das universidades federais foram criados 79 campus de universidades federais pré-existentes, sendo $20 \%$ na região norte; $20 \%$ na região sul; $5 \%$ na região centro-oeste, $39 \%$ na região nordeste e $16 \%$ na região sudeste.

A segunda fase do programa de expansão tem início com a vigência do Plano de Reestruturação e Expansão das Universidades Federais - REUNI. Instituído por meio do decreto $n^{\circ} 6.096$ (24/04/07) com o objetivo de "[...] criar condições para a ampliação do acesso e permanência na educação superior (por meio do), melhor aproveitamento da estrutura física e dos recursos humanos atualmente existentes" (art. $\left.1^{\circ}\right)$.

Com o REUNI, o governo fomentou a expansão do ensino superior público, com foco na graduação, por meio da racionalização dos recursos e pela utilização máxima da capacidade de operação das IFES, por meio de contratos de gestão pelos quais recebem verbas públicas pelo cumprimento das metas assumidas, dentro de prazos estabelecidos e mediante indicadores quantitativos. A pretensão do Programa é atingir um aumento substancial de ingressantes nas IFES e tem como metas principais: a elevação da taxa de conclusão dos alunos para $90 \%$ e o aumento da relação aluno/professor para 18. 


\section{movimento \\ faculdade de educação - programa de pós-graduação em educação universidade federal fluminense \\ issn 2359-3296 \\ ano 5 número 8 - 2018}

O REUNI trouxe medidas de extremo impacto sobre a educação superior pública. A partir dele, o governo pretendeu aprofundar e consolidar um novo modelo de universidade, mais eficiente, flexível e competitiva. Portanto, "[...] para atender a essa lógica, a universidade estruturada no tripé ensino-pesquisa-extensão com regime de tempo integral e dedicação exclusiva, além de ser considerada cara, torna-se desnecessária" (ANDES, 2007, p. 21).

De acordo com o relatório "Análise sobre a expansão das universidades federais - 2003 a 2012"26, de 2003 a 2010, houve um salto de 45 para 59 universidades federais, o que representa uma ampliação de 31\%. Além disso, houve um aumento de 148 para 274 campi/unidades, o que representa um crescimento de 85\%. A interiorização das universidades e dos campi proporcionou uma elevação no número de municípios atendidos: de 114 para 272, com um crescimento de 138\%. O Relatório também aponta o crescimento de aproximadamente $111 \%$ do número de vagas na graduação presencial e também nas matrículas, tanto na graduação presencial (60\%) quanto na modalidade à distância (520\%). Na pósgraduação, houve aumento de 90\% no período de 2003 a 2011.

Com relação ao quantitativo de docentes, o Relatório aponta que houve uma expansão de $44 \%$ no total no período de 2003-2012. Além do incremento na contratação de professores efetivos, com a criação de 21.786 vagas entre 2008 e 2012, bem como ampliação da qualificação dos quadros das IFES, que em 2012 passaram a contar com 68,78\% de seus docentes com titulação de doutor.

Em que pese a efetiva ampliação e qualificação do quadro de professores das IFES, o estudo realizado por Chaves e Mendes (2009) aponta um processo de intensificação do trabalho docente fomentado com a expansão, pois, se por um lado, as metas de aumento dos cursos, das vagas e das matrículas variam de

26 Relatório da comissão constituída pela Portaria do MEC no 126/2012. Disponível em: http://reuni.mec.gov.br/index.php?option=com_content\&view=article\&id=100\&ltemid=81. 


\section{movimento \\ faculdade de educação - programa de pós-graduação em educação universidade federal fluminense \\ issn 2359-3296 \\ ano 5 número 8 - 2018}

60 a 200\%, dependendo da Universidade, por outro, a contratação de docentes varia de 15 a 30\% (CHAVES; MENDES, 2009, p. 58). Isso demonstra uma das maiores fragilidades do processo de expansão: a intensificação do trabalho docente, pois para acompanhar o ritmo da expansão os mesmos têm suas cargahorárias de trabalho ampliada em função das demandas oriundas do ensino de graduação, restando pouco tempo para o desenvolvimento de atividades de pesquisa e de extensão. Além disso, muitos assumem atividades administrativas, sobretudo devido à defasagem do quadro técnicoadministrativo ${ }^{27}$, conforme apontam estudos do ANDES-SN (2013a; 2013b).

A flexibilização das modalidades de contratação de professores aberta com 0 REUNI $^{28}$ também contribui para esse quadro, uma vez que se torna mais vantajoso a contratação de professores substitutos em regime parcial e sem vínculos duradouros com a instituição, o que cria uma subcategoria docente. Obviamente que tudo isso sob o ponto de vista da lógica geral do Programa de expansão com contenção de recursos.

Com relação aos recursos investidos na expansão das IFES, o Relatório da Comissão aponta um total de $\mathrm{R} \$$ 9.996.296.234,00 entre investimentos e custeios no período de 2005 a 2012. Nesse aspecto, percebe-se que a retórica reformista não resiste à lógica da realidade concreta, já que, no bojo de um estado capitalista, a destinação do fundo público é objeto de disputa e os interesses das classes dominantes são preponderam. Em que pese o governo

\footnotetext{
${ }^{27}$ De acordo com dados do Relatório, o segmento teve uma expansão de 16\%, de 2003 a 2012 , considerando a reposição dos quadros por aposentadoria, vacância, óbitos, exonerações e contratações via concursos.

${ }^{28}$ Portaria Normativa Interministerial MEC/MPOG n. 22/2007 e n. 224/2007, que instituem em cada universidade federal um "banco de professores-equivalentes", no qual cada docente tem um "peso", conforme a titulação e o regime de trabalho. Tal portaria estimula a contratação de docentes substitutos em tempo parcial, que possuem um "peso" menor que o decente efetivo com dedicação exclusiva, permitindo um aumento de contratações sem extrapolar os limites estabelecido pelo Banco. Outra medida, foi o decreto no. 7.485/2011 que permite que até $20 \%$ do quadro docente efetivo das IFES seja composto por professores substitutos.
} 


\section{movimento \\ faculdade de educação - programa de pós-graduação em educação universidade federal fluminense \\ issn 2359-3296 \\ ano 5 número 8 - 2018}

alardear um alto investimento na expansão da rede federal de ensino superior, com o objetivo de promover a "democratização" do acesso, a análise do financiamento não deixa margens para dúvidas. Vejamos as informações que seguem.Em primeiro lugar, o aumento real dos gastos públicos com as universidades federais não foi proporcional ao crescimento das receitas da União no período. Dados compilados por Reis (2016, apud LÉDA et al. 2016) apontam para a progressiva redução dos recursos aplicados nas IFES entre 2003 e 2014 em relação ao total das receitas com a função educação.

Assim, apesar de as despesas com a educação terem aumentado, a parcela destinada às universidades federais diminuiu em $22,46 \%$ no período. Essa é a mesma conclusão de Chaves (2015) quando aponta que as despesas com as universidades federais passaram de $64,46 \%$ para $39,99 \%$ das destinadas à função educação entre 2003 e 2012, apesar da forte expansão do quantitativo de vagas e matrículas.

Concluímos que o discurso do governo de que as IFEs teriam recebido mais recursos nos últimos anos, desconsidera o aumento da receita da União, bem como a expansão das matrículas ocorrida nesse período, concomitantemente com a criação de novas Universidades e campi (CHAVES, 2015, p. 436).

Portanto, ao contrário do que o governo afirma, houve de fato uma redução percentual dos gastos com as universidades públicas no período de expansão, acarretando a precarização das instituições, uma vez que tiveram de atender a uma demanda bem maior com recursos que não aumentaram na mesma proporção.

Após o término da vigência do REUNI, houve um esgotamento da capacidade das IFES quanto à manutenção das unidades e dos cursos criados durante 0 Programa. As instituições mergulharam em uma situação crítica, agravada pelos progressivos cortes e contingenciamentos de recursos para financiamento. As 


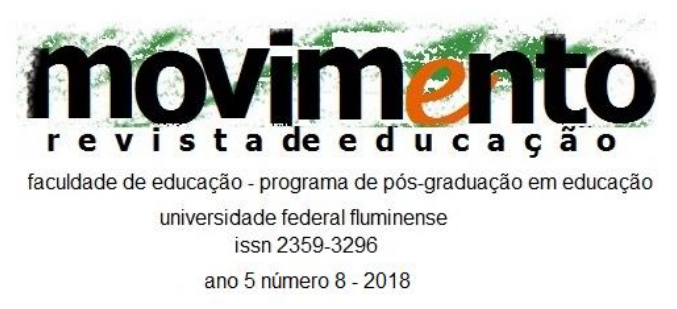

medidas de ajuste fiscal adotadas pelo governo federal para conter a crise econômica, a partir de 2015, agravaram ainda mais o quadro.

O contingenciamento dos recursos do Ministério da Educação - na ordem de aproximadamente $R \$ 12$ bilhões em 2015 (ANDES, 2015) - representa um montante que ultrapassa os $R \$ 9$ bilhões investidos na expansão desordenada da Educação Federal.

Isso demonstra que o governo freia o próprio processo que ele tinha criado, agindo contra o seu próprio programa [em referência ao Reuni]. Além disso, reduz proporcionalmente o investimento na universidade pública e aumenta os recursos para o lucro das empresas (ANDES, 2015).

Por outro lado, os recursos públicos transferidos para o setor privado parecem não ter sido afetados, já que os recursos do Ministério da Educação para o FIES foram da ordem de $\mathrm{R} \$ 20$ bilhões no auge da crise econômica em 2016, enquanto as Universidades públicas ficam à mercê dos cortes e dos contingenciamentos impostos pela equipe econômica, o que compromete sua capacidade real de funcionamento.

\section{Considerações Finais}

Para finalizar essa breve análise sobre as políticas para o ensino superior no período de 2003 a 2012, resta apresentar um balanço no sentido do alcance do alardeado objetivo de "democratização" da educação superior.

De acordo com os números da expansão, houve crescimento de matrículas no ensino superior de $86 \%$ no setor privado e de $61 \%$ no público de 2003 a 2012 . Do total de 7.037 .688 matrículas em 2012, apenas 1.897 .376 pertenciam a rede pública contra 5.140.312 da privada. Conforme chama atenção o Caderno do GEA (2012, p. 22), de 1999 a 2003, o crescimento do total de matrículas na 


\section{movimento \\ faculdade de educação - programa de pós-graduação em educação universidade federal fluminense \\ issn 2359-3296 \\ ano 5 número 8 - 2018}

educação superior foi de 66\%, contra apenas 16\% entre 2003 e 2007 e de $28 \%$ de 2007 a 2011.

Em relação ao quantitativo de instituições, verifica-se a tendência de um crescimento maior das instituições públicas no período, sobretudo devido aos programas de expansão da rede federal. Considerando a extensão de $30 \%$ no total de IES, as instituições públicas tiveram um crescimento de 46,9\%, enquanto as privadas, de $27,1 \%$. No entanto, Chaves (2015) esclarece que a fusão de instituições privadas e a compra de instituições pequenas ou médias por grandes redes podem justificar esse dado em relação ao crescimento do número de IES privadas. Por outro lado, isso não compromete o crescimento do setor, que se torna cada vez mais atrativo para o capital, pois a rede privada concentra $87,41 \%$ das instituições e a pública possui apenas $12,58 \%$ do total.

Considerando o período como um todo, apesar do maior crescimento da rede pública e tendo em vista a defasagem histórica do setor ${ }^{29}$, a rede privada ainda concentra a maioria das matrículas e das instituições, o que aponta que o esforço para a expansão do ensino público não foi capaz de reverter a tendência histórica de crescimento do privado na educação superior, impondo um sério limite a sua democratização.

Pelo contrário, chama atenção o crescimento da participação do setor privado, o qual já ultrapassa $80 \%$ das matrículas. Além disso, há uma forte concentração dessas matrículas em instituições vinculadas a grupos empresariais, associados a fundos de investimento, que iniciaram o seu processo de abertura de capital em 2007, estimulado pelas políticas recentes ${ }^{30}$. Desde que começaram suas operações na bolsa de valores, as ações dos principais grupos empresariais de

29 Dados do INEP apontam que na década de 1990, de 1991 a 2001, houve uma redução no quantitativo de IES públicas, de 222 para 183, um déficit de 17,5\%.

${ }^{30}$ Ver Setti (2014). 


\section{movimento \\ faculdade de educação - programa de pós-graduação em educação universidade federal fluminense \\ issn 2359-3296 \\ ano 5 número 8 - 2018}

educação no país têm tido resultados surpreendentes ${ }^{31}$, o que aponta para um outro fenômeno conhecido como "oligopolização". Conforme apontam Bianchetti e Sguissardi (2017, p. 99-100):

O que de fato se verifica no setor privado, nos últimos anos, já não é mais a expansão, ocorrida em anos anteriores, do número de IES e de matrículas privadas, mas um processo de concentração e fortalecimento patrimonial e de receita em fenômeno que aqui se denominou de "oligopolização", em que pouco mais de que uma dezena de megaempresas do mercado educacional detêm mais de um terço do total de matrículas inscritas em cerca de 1.900 instituições privadas.

Do outro lado da moeda, as universidades federais não desfrutam de uma situação tão auspiciosa. Já mencionamos que o esgotamento do ciclo expansionista do ensino superior público e a atual crise econômica e fiscal do Estado, somados a forma precarizada com que se realizou a expansão, deixaram um legado amargo para as universidades públicas, as quais não têm garantia de recursos suficientes para manutenção de suas atividades ${ }^{32}$.

Outros aspectos relativos ao legado da ampliação das IFES se referem ao agravamento de problemas devido ao processo de expansão. De acordo com apuração do ANDES-SN (2013a; 2013b), o REUNI não cumpriu as metas determinadas pelo próprio governo e ainda agravou as condições de funcionamento das IFES em muitos casos.

As consequências mais visíveis desse processo se apresentam por meio da cristalização das condições de precariedade instaurada nas unidades criadas pós-REUNI, como: obras inacabadas; falta de espaços para a realização de atividades acadêmicas de forma plena, com segurança e conforto para

\footnotetext{
31 Ver Bianchetti e Sguissardi (2017).

${ }^{32}$ Segundo Leher (apud POLI,2017) a maior parte das universidades federais recebeu em 2016 metade dos recursos de investimento em comparação a 2014 e, para 2017, a expectativa é de uma diminuição de aproximadamente $12 \%$ dos recursos das IFES.
} 


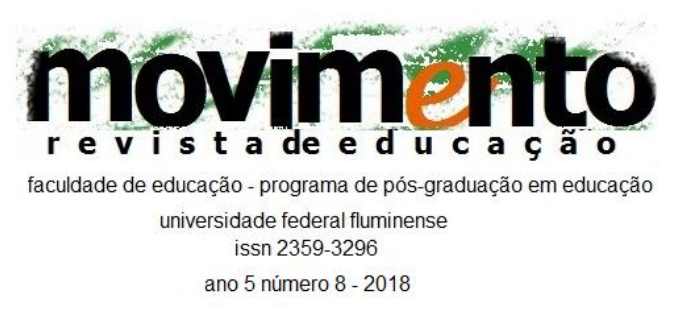

professores e alunos; adoecimento docente, em função da sobrecarga de trabalho gerada pelo processo de expansão e pela precarização das condições de trabalho, além do já mencionado produtivismo acadêmico, que fomenta a competitividade entre os pares; hierarquização da categoria (docentes vinculados a programas de pós-graduação e que realizam pesquisa e docentes dedicados quase exclusivamente ao ensino de graduação), que provoca sofrimento nos docentes que não têm como progredir na carreira, nos termos exigidos por muitas universidades, sobretudo aqueles lotados nas unidades interiorizadas; a cisão de instituições e cursos, entre "escolões de $3^{\circ}$. Grau" e "centros de excelência", dentre outras (ANDES, 2013a; 2013b).Tal quadro tem fomentado o esvaziamento da formação; o aligeiramento dos cursos e da certificação em larga escala; tendência à queda na qualidade das pesquisas e do conhecimento produzido pela universidade e o aprofundamento da heteronomia.

Cabe ainda apontar um último aspecto fundamental para um olhar mais concreto sobre as políticas de expansão do ensino superior: o alcance das metas de ampliação das matrículas nesse nível de ensino, conforme preconizadas pelo PNE (2001-2011), e que justificou as políticas de expansão no período em grande medida. Pela análise dos dados do IBGE - no que se refere à faixa etária - e dos dados do INEP - referentes às matrículas - observa-se que estamos ainda muito aquém do alcance da referida meta, tendo em vista que a taxa líquida de matrícula no ensino superior era de apenas $17 \%$ até 2011 , chegando a 18\% em 2015 (CADERNOS DO GEA, 2012).

Portanto, em que pese todo o esforço empreendido no sentido da expansão do ensino superior, os resultados alcançados são ainda tímidos, o que nos leva a concluir que: "[...] a democratização no ensino superior e garantia de não evasão e conclusão do curso superior depende de políticas de inclusão social, de 


\section{movimento \\ faculdade de educação - programa de pós-graduação em educação universidade federal fluminense \\ issn 2359-3296 \\ ano 5 número 8 - 2018}

distribuição de renda, de erradicação da indigência e da pobreza" (SGUISSARDI, 2009, p. 51).

Em suma, esse quadro nos leva a pensar que a contrarreforma do ensino superior em curso se insere em uma lógica mais profunda, qual seja, a de adequar a educação superior aos interesses do capital mundializado no sentido convertê-la em uma mercadoria - "educação-mercadoria" - que pode ser adquirida pelos indivíduos no mercado educacional, e como insumo "mercadoria-educação"33 - no sentido da formação da força de trabalho mais adequada aos interesses do capital na chamada "sociedade do conhecimento".

Nesse sentido, corroboramos a análise de Minto (2014) acerca do atual momento de reforma da educação superior no sentido de adequá-la à lógica do capital e de atender às funções que se espera desse tipo de ensino. No atual estágio de acumulação capitalista, os detentores do capital necessitam cada vez mais se apropriarem de todas as esferas da reprodução social no sentido da produção de mais-valia. Com a educação não seria diferente. Assim,

A educação, setor estratégico, vive então seu momento de "glória": de um lado, cumpre a função ideológica de servir ao capital; e, de outro, surge como um campo aberto à acumulação de capital, sem quaisquer impedimentos éticos ou políticos. [...] Não se trata apenas da "desresponsabilização do Estado" para com a educação. O que ocorre também é uma reorientação das formas e dos mecanismos que o Estado utiliza para atender às necessidades do capital, dentre as quais o ensino superior ocupa lugar importante. Refere-se à efetiva transformação das IES e suas atividades em nichos de acumulação capitalista (MINTO, 2014, p. 367).

33 A análise dos termos "educação-mercadoria" e "mercadoria-educação" se encontra em Rodrigues (2007). 


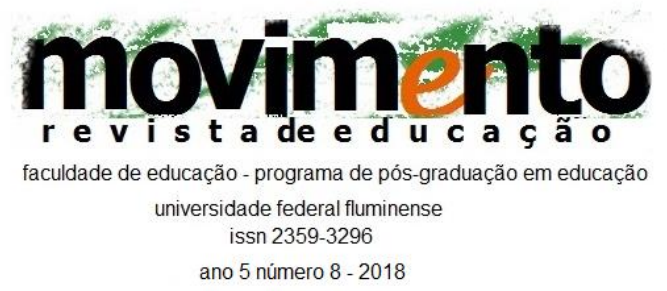

\section{Referências}

ANDES-SN. Governo anuncia novo corte na Educação Federal e libera mais R\$ 5 bi para o FIES (31/07/2015). Disponível em https://grevenasfederais.andes.org.br/2015/07/31/governoanuncia-novo-cortena-educacao-federal-e-libera-mais-r-5-bi-para-o-fies/. Acesso em 16 de abril de 2016.

Revista ANDES Especial. Dossiê Nacional no. 3. Precarização do trabalho docente I. Brasília-DF, abril. 2013 (a).

. Revista ANDES Especial. Dossiê Nacional no. 3. Precarização do trabalho docente II. Brasília-DF, novembro. 2013 (b).

As novas faces da reforma universitária do governo Lula e os impactos do PDE sobre a educação superior. Brasília - DF, Caderno Andes N. 25, agos. 2007.

ANTUNES, R. A desertificação neoliberal no Brasil (Collor, FHC e Lula).

Campinas, SP: Autores Associados, 2004.

BANCO MUNDIAL. Construir sociedades de conocimiento: nuevos desafios para la educación terciaria. Washington, 2003. Disponível em www.bancomundial.org.br acesso em dez/2014.

BIANCHETTI, L; SGUISSARDI, V. Da universidade à commodicydade: ou de como e quando, se a educação/formação é sacrificada no altar do mercado...Campinas, SP: Mercado das Letras, 2017.

BOITO JR., A. A hegemonia neoliberal no governo Lula. Crítica Marxista, v.17, p. 9-35, 2003. Disponível em:

https://www.ifch.unicamp.br/criticamarxista/arquivos biblioteca/critica17-Aboito.pdf, acesso em 10/05/2017.

BRASIL. Ministério da Fazenda. Secretaria de Política Econômica. Gasto social do governo central 2001-2002. Brasília-DF, novembro de 2003. Disponível em: http://www.fedepsp.org.br/superior/gasto social 01 02.pdf. Acesso em abril de 2017.

. PRESIDÊNCIA DA REPÚBLICA - GRUPO DE TRABALHO

INTERMINISTERIAL. Bases para o enfrentamento da crise emergencial das universidades brasileiras e roteiro para a reforma da universidade brasileira. Brasília, 2003. . A democratização e expansão do ensino superior no país (2003-2014). Brasília, DF, 2014. Disponível em: 


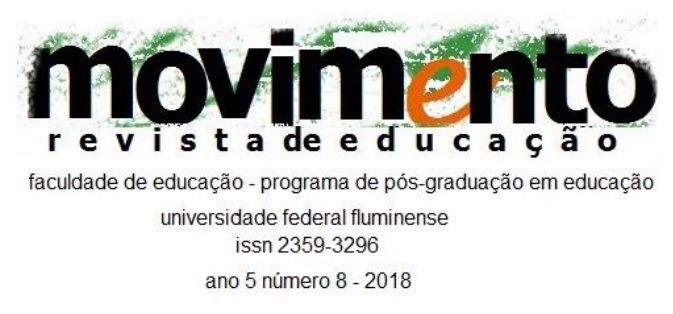

http://portal.mec.gov.br/index.php?option=com docman\&view=download\&alias $=16762$-balanco-social-sesu-2003-2014\&ltemid=30192. Acesso em dezembro de 2017CADERNOS DO GEA . - n.3 (jan./jun. 2013). - Rio de Janeiro : FLACSO, GEA; UERJ, LPP, 2012.

CASTELO, R. O social-liberalismo: auge e crise da supremacia burguesa na era neoliberal. - São Paulo: Expressão Popular, 2013.

CASTELO BRANCO, R. O novo-desenvolvimentismo e a decadência ideológica do estruturalismo latino-americano. IN: OIKOS, Rio de Janeiro, Volume 8, n. 1, 2009 (págs. 71-91). Disponível em: www.revistaoikos.org. Acesso em agosto de 2017.

CÊA, G. S. dos S. As versões do anteprojeto de lei da reforma da educação superior: princípios, impasses e limites. IN SIQUEIRA, A. C de; NEVES, L.M.W. (orgs.). Educação superior: uma reforma em processo. - São Paulo: Xamã, 2006 (p. 43-79).

CHAVES, V.L.J. Política de financiamento e a expansão da educação superior no Brasil: o público e o privado em questão. IN ETD - Educ. temat. digit. Campinas, SP v.17 n. 2 p. 427-441, maio/ago. 2015. Disponível em http://periodicos.sbu.unicamp.br/ojs/index.php/etd.

CHAVES, V.L.J; MENDES, O. da C. REUNI: o contrato de gestão na reforma da educação superior pública. IN CHAVES, CABRAL NETO, NASCIMENTO (orgs). Políticas da educação superior no Brasil: velhos temas, novos desafios. São Paulo: Xamã, 2009.

CHAUÍ, M. Escritos sobre a universidade. - São Paulo: Editora da UNESP, 2001.

COUTINHO. C.N. O Estado Brasileiro: gênese, crise, alternativas. In: LIMA, J. C. F. e NEVES, L. M. W. (Orgs.) Fundamentos da educação escolar do Brasil contemporâneo. Rio de Janeiro: Fiocruz, 2006, p.173-200.

DIAS, E. F. Política brasileira: embate de projetos hegemônicos. São Paulo: Editora Instituto José Luís e Rosa Sundermann, 2006. (Série Polêmicas, 4).

FRIGOTTO, G. A gênese das teses do Escola sem Partido: esfinge e ovo da serpente que ameaçam a sociedade e a educação. FRIGOTTO, G. (org.). Escola "sem" partido: a esfinge que ameaça a educação e a sociedade brasileira. Rio de Janeiro, UERJ, LPP, 2017. 


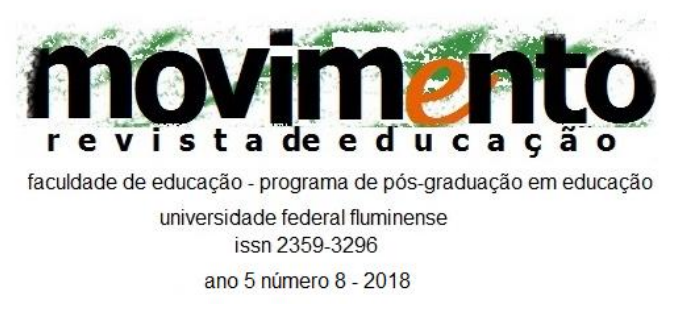

LÉDA, D. et al. Crise econômica e interiorização na UFMA: repercussões sobre o trabalho docente em alguns campi do continente. Anais do XXIV Seminário nacional UNIVERSITAS/BR, Universidade Estadual de Maringá, maio de 2016.

LIMA, K. Reforma da educação superior nos anos de contra-revolução neoliberal: de Fernando Henrique Cardoso a Luis Inácio Lula da Silva. Universidade Federal Fluminense (Tese de Doutorado), 2005.

. O Programa Reuni e os desafios para a formação profissional em Serviço Social. IN Revista Katálysis, Florianópolis, v. 16, n. 2, p. 258-267, jul./dez. 2013.

. Brasil em tempos de contrarrevolução. IN Universidade e Sociedade. Ano XXVII - no. 59- janeiro de 2017 (p. 92-103).

MACIEL, D. "Melhor impossível": a nova etapa da hegemonia neoliberal sob o governo Lula. IN Universidade e sociedade. Brasília-DF, Ano XX, no. 46, Julho de 2010.

MANCEBO, D.; MAUÉS, O.; CHAVES, V. L. J. Crise e reforma do Estado e da universidade brasileira: implicações para o trabalho docente. Educar, Curitiba, n. 28, p. 37-53, 2006. Editora UFPR.

MANCEBO, D. Trabalho docente na pós-graduação. IN Universidade e sociedade. - Brasília, DF. Ano XXI, no. 48, jul. 2011.

. A universidade neoprofissional, heterônoma e competitiva. In: MANCEBO, Deise; FÁVERO, Maria de Lourdes de A. (Orgs.). Universidade: políticas, avaliação e trabalho docente. São Paulo: Cortez, 2004, p. 33-53; p. 41-43.

MINTO, L.W. A educação da "miséria": particularidade capitalista e educação superior no Brasil. São Paulo: Outras Expressões, 2014.

NEVES, M. L.W; PRONKO, M.A. O mercado do conhecimento e o conhecimento para o mercado. - Rio de Janeiro: EPSJV, 2008.

OLIVEIRA, F. de. Brasil: uma biografia não autorizada. São Paulo: Boitempo, 2018.REVISTA POLI. Saúde, educação e trabalho. Ano IX, no. 50 mar./abr. 2017.

RODRIGUES, J. Os empresários e a educação superior. Campinas, SP: Autores Associados, 2007. 


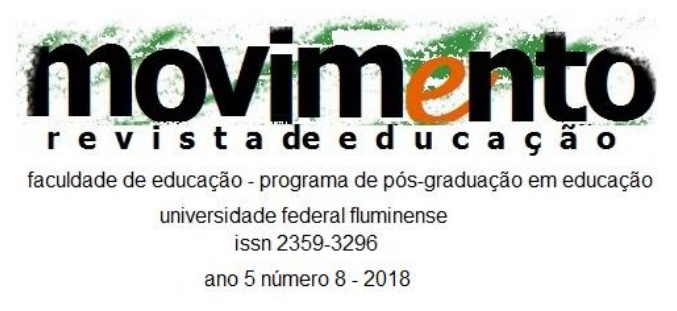

ROSAR, M. de F. F. Movimentos sociais, educação e revolução. IN. ORSO, J.P; MALACHEN, J; CASTANHA, A.P. (orgs). Pedagogia histórico-crítica, educação e revolução: 100 anos da revolução russa. - Campinas, SP: Armazém do Ipê, 2017 (p. 101-124).

SAMPAIO JR. P. de A. Desenvolvimentismo e neodesenvolvimentismo: tragédia e farsa. IN Serv. Soc. Soc., São Paulo, n. 112, p. 672-688, out./dez. 2012.

SETTI, R. Programas federais mantêm educação em alta na Bolsa. O Globo. Economia. 16/04/2014. Disponível em : https://www.blogsoestado.com/uniblog/files/2014/07/Programas-federaismant\%C3\%AAm-educa\%C3\%A7\%C3\%A3o-em-alta.pdf. Acesso em 22/04/2017.

SGUISSARDI, V. Universidade brasileira no século XXI: Desafios do presente. São Paulo: Cortez, 2009.

SINGER, A. Raízes sociais e ideológicas do Lulismo. IN Novos estudos, no. 85, nov. de 2009.

UNESCO. Declaração Mundial de Educação Superior no Século XXI: visão e ação. Unesco, 1998. Disponível em:

http://www.direitoshumanos.usp.br/index.php/Direito-a-

Educa\%C3\%A7\%C3\%A3o/declaracao-mundial-sobre-educacao-superior-noseculo-xxi-visao-e-acao.html. Acesso em: maio de 2017.

\section{SOBRE AS AUTORAS}

DENISE BESSA LÉDA é Doutora em Psicologia Social - Universidade do Estado do Rio de Janeiro. Professora da Universidade Federal do Maranhão.

E-mail: denisebl@uol.com.br

ANA PAULA RIBEIRO DE SOUSA é doutoranda do programa de Pósgraduação em Educação da Universidade Federal Fluminense. Professora da Universidade Federal do Maranhão.

E-mail: anapaularis@hotmail.com 